EUROPEAN CENTRAL BANK

ECB WORKSHOP ON THE ANALYSIS OF THE MONEY MARKET

\section{WORKING PAPER SERIES NO 976 / DECEMBER 2008}

\title{
THE TERM STRUCTURE OF INTEREST RATES ACROSS FREQUENCIES
}

by Katrin Assenmacher-Wesche and Stefan Gerlach

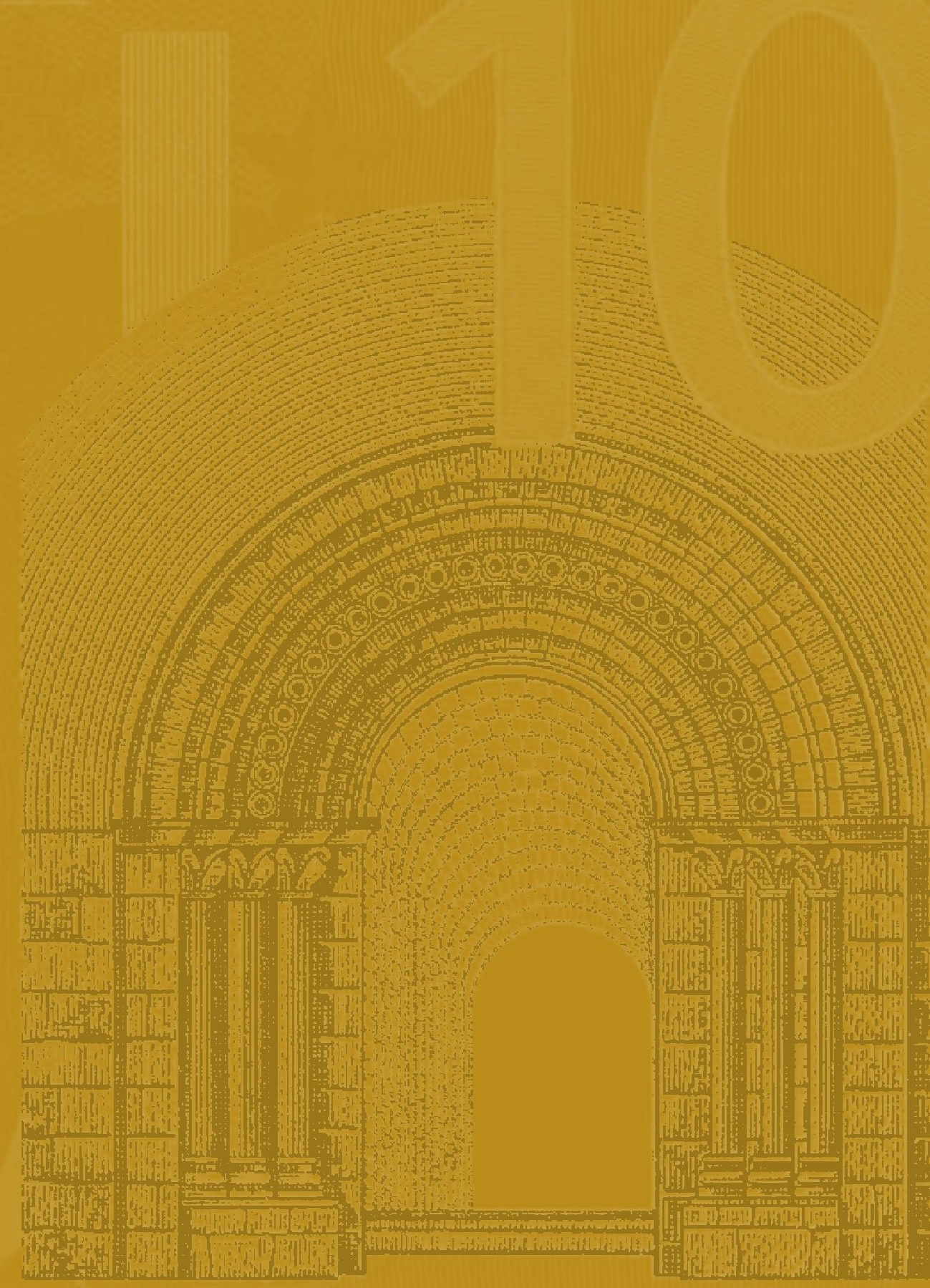




\author{
ECB WORKSHOP \\ ON THE ANALYSIS OF \\ THE MONEY MARKET

\section{THE TERM STRUCTURE OF INTEREST RATES ACROSS FREQUENCIES '} \\ by Katrin Assenmacher-Wesche ${ }^{2}$ \\ and Stefan Gerlach ${ }^{3}$
}

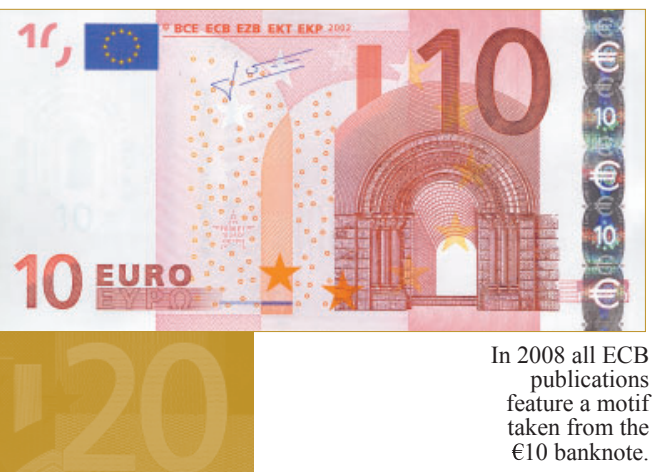

This paper can be downloaded without charge from http://www.ecb.europa.eu or from the Social Science Research Network electronic library at http://ssrn.com/abstract_id=131061|.

I The views expressed in this paper are solely the responsibility of the authors and should not be interpreted as reflecting the views of the SNB or the European Central Bank. We are grateful to Alain Durré, Eric Jondeau, Paul Söderlind, an anonymous referee of the ECB. Working Paper series and participants at a seminar at the Bundesbank, the annual meeting of the Swiss Society of Economics and Statistics and an $E C B$ workshop on "The analysis of the money market: role, challenges and implications from the monetary policy 
On 14 and 15 November 2007, Alain Durré, Huw Pill and Diego Rodriguez-Palenzuela of the ECB's Monetary Policy Stance Division organised a central bank workshop titled "The Analysis of the Money Market: Role, Challenges and Implications from the Monetary Policy Perspective". This workshop provided an opportunity for participating central bank experts to exchange views and foster debate, also in interaction with international organizations and academic institutions. The first day of the workshop addressed issues related to the macro-perspective of the money market, drawing on the experiences of a large number of countries. The second day adopted a micro-perspective on the money market, looking in particular at trading behaviour in the overnight money market and its implications for the evolution of spreads.

A first version of this paper was presented at this workshop. The papers presented at the time of the workshop did not consider the potential implications of the financial turmoil for the results of the paper, given that the tensions in money markets emerged in August 2007. The published version of these papers represents an update of the original paper, which incorporates the discussion which took place at the workshop and in most cases a discussion on the developments in the money markets since August 2007.

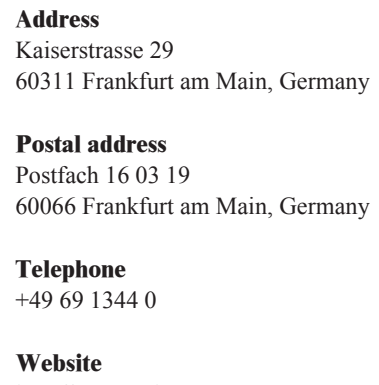




\section{CONTENTS}

Abstract

Non-technical summary

1 Introduction

2 Brief review of the literature

3 Empirical work

4 The data

5 Empirical methods and results

5.1 Regression results

5.2 Monetary policy and the relative importance of the term premium

6 Conclusions

Appendix

References

Tables and figures

European Central Bank Working Paper Series 


\begin{abstract}
This paper tests the expectations hypothesis $(\mathrm{EH})$ of the term structure of interest rates in US data, using spectral regression techniques that allow us to consider different frequency bands. We find a positive relation between the term spread and the change in the long-term interest rate in a frequency band of 6 months to 4 years, whereas the relation is negative at higher and lower frequencies. We confirm that the variance of term premia relative to expected changes in long-term interest rates dominates at high and low frequencies, leading the $\mathrm{EH}$ to be rejected in those bands but not in the intermediate frequency band.
\end{abstract}

Keywords: Expectations theory of the term structure, interest rates, spectral regression, frequency domain.

JEL Classification: C22, E43. 


\section{Non-technical summary}

The term structure of interest rates, or the yield curve, is a central element in much of modern monetary and financial economics. It is also an important concept for financial institutions. Given its central role in both theory and practice, it is unfortunate that the main body of theory developed to understand the term structure - the expectations hypothesis $(\mathrm{EH})$, which holds that long interest rates are determined by the expected future path of short-term interest rates plus a constant, but potentially maturity-dependent, term premium - has been resoundingly rejected by large number of studies using data from different countries, time periods and maturity segments.

In this paper we test the $\mathrm{EH}$ of the term structure of interest rates in US data, using spectral techniques that allow us to consider different frequency bands. In particular, we explore the hypothesis that the predictability of future changes in short-term interest rates varies across frequency bands as a consequence of the conduct of monetary policy. At high frequencies corresponding to periodicities of less than six months, the predictability of changes in future interest rates may be small, so that movements in the term structure are dominated by term premia, leading the $\mathrm{EH}$ to be rejected. By contrast, in the intermediate, or business-cycle, frequency band corresponding to periodicities of between six months and four years, shortterm rates may contain a relatively large predictable component as a consequence of the conduct of monetary policy. If so, it may be difficult to reject the $\mathrm{EH}$ although the presence of a time-varying term premium renders it, strictly speaking, false. Finally, at low frequencies changes in short-term rates may again be difficult to forecast, for instance because there is in fact little variation in the expected future path of short-term interest rates in this frequency band. If, however, term premia do exhibit variations at long frequencies, the $\mathrm{EH}$ will again be rejected.

We find that the slope coefficient on the term spread changes sign across frequency bands. At high frequencies, defined as fluctuations with a periodicity of less than 6 months, we find a negative relation between the term spread and the change in the long-term interest rate. In an intermediate frequency band, corresponding to a time horizon of 6 months to 4 years, we generally cannot reject a unit coefficient in a regression of the future change in the long rate on the term spread, whereas at low frequencies beyond 4 years the relation is positive for short maturities and negative for longer maturities. We conjecture that the variance of the term premium relative to expected changes in the long rate varies across frequency bands and find some support in the data for this hypothesis. While our approach does not allow us to isolate the absolute variability the term premium, we interpret our results as indicating that the 
predictability of interest rates varies across frequency bands as a consequence of the conduct of monetary policy.

These findings have two implications for monetary policy makers and central bank watchers. First, to the extent that the $\mathrm{EH}$ is rejected because market participants can not form expectations of future interest rates, high levels of transparency in setting and conducting monetary policy seem desirable. Bonds and other securities will experience relatively large and undesirable valuation gains and losses in response to unpredicted changes in monetary policy. Greater transparency makes monetary policy more predictable and reduces the severity of such valuation changes.

Second, since the rejection of the EH appears largely due to high-frequency fluctuations in the data and the EH seems to do a better job accounting for interest rates changes in intermediate frequency bands, the slope of the yield curve is a useful measure of market participants' expectations of changes in monetary policy. However, short-run or high frequency fluctuations in the term structure of interest rates do not seem to contain much information about future interest rates and should be disregarded. 


\section{Introduction}

The term structure of interest rates, or the yield curve, is a central element in much of modern monetary and financial economics. It is also an important concept for financial institutions. For instance, a whole range of financial assets is priced off the yield curve for government securities. The term structure plays a central role in monetary policy making, too. Thus, the spread between long nominal and real yields is used by many central banks to gauge inflation expectations and the credibility of the monetary policy regime; the slope of the term structure is used to assess the probability of recessions; and the entire yield curve is used to assess market expectations about the future course of monetary policy.

Given its central role in both theory and practice, it is unfortunate that the main body of theory developed to understand the term structure - the expectations hypothesis $(\mathrm{EH})$, which holds that long interest rates are determined by the expected future path of short-term interest rates plus a constant, but potentially maturity-dependent, term premium - has been resoundingly rejected by large number of studies using data from different countries, time periods and maturity segments. Despite this, the theory continues to be used to interpret interest-rate movements by analysts in the academic, financial and central-banking sectors alike. One reason for that may be that while time-varying term premia appear to be present and lead to a statistical rejection of the theory, these are small enough for the $\mathrm{EH}$ to be seen as a useful tool for understanding movements in the term structure (Campbell and Shiller 1987, 1991).

In this paper we use US data to explore the hypothesis that the predictability of future changes in short-term interest rates varies across frequency bands as a consequence of the conduct of monetary policy. At high frequencies corresponding to periodicities of less than six months, the predictability of changes in future interest rates may be small, so that movements in the term structure are dominated by term premia, leading the $\mathrm{EH}$ to be rejected. By contrast, in the intermediate, or business- 
cycle, frequency band corresponding to periodicities of between six months and four years, short-term rates may contain a relatively large predictable component as a consequence of the conduct of monetary policy. If so, it may be difficult to reject the $\mathrm{EH}$ although the presence of a time-varying term premium renders it, strictly speaking, false. Finally, at low frequencies changes in short-term rates may again be difficult to forecast, for instance because there is in fact little variation in the expected future path of short-term interest rates in this frequency band. If, however, term premia do exhibit variations at long frequencies, the $\mathrm{EH}$ will again be rejected.

The paper is structured as follows. The next section provides a review of some of the relevant literature testing the expectations hypothesis. Several authors have demonstrated that the empirical performance of the $\mathrm{EH}$ depends on the variability of the term premium relative to the variability of expected changes in future interest rates. We set out our hypothesis that the performance of the $\mathrm{EH}$ may vary across frequency bands in Section 3. Section 4 discusses the data and Section 5 presents our empirical methodology and the results. Using band spectrum regression we find that the EH cannot be rejected in a frequency band of 6 to 48 months. Moreover, the variability of the term premium relative to the variability of expected changes in the future long-term rate is smallest in this frequency band, as compared to lower and higher frequencies. Section 6 offers some conclusions.

\section{Brief review of the literature}

This paper is related to two strands of the literature on the term structure of interest rates. The first of these was initiated by Mankiw and Miron (1986) who argue that the EH will fare poorly in episodes in which the central bank conducts policy in such as way as to make it difficult for financial market participants to forecast future changes in short-term interest rates. The explanation is simple. When the expected path of short-term interest rates is horizontal, movements in the term structure will be dominated by changes in the risk premium. Since tests of the $\mathrm{EH}$ assume that risk premia are constant, they will then reject the null hypothesis. By contrast, if the 
central bank sets monetary policy in such a way as to make future changes in interest rates easy to predict, for instance because it moves short-term interest rates in response to the output gap, movements in the term structure may be dominated by changes in the expected path of interest rates, leading the EH to be accepted. Mankiw and Miron (1986) study data around the establishment of Federal Reserve System, which led to a pronounced dampening of the highly predictable seasonal component of interest rates, and find support for their hypothesis.

Gerlach and Smets (1997) provide more evidence in support of Mankiw and Miron's hypothesis. Using data from 17 economies on short-term euro-currency interest rates, they find that the $\mathrm{EH}$ is not rejected in those economies in which one-month interest rates are relatively easily predictable. Gerlach and Smets (1998), in a closely related study, note that the EH tends not be rejected in economies with fixed exchange rates, essentially because occasional episodes of exchange-market pressures have led to spikes in short-term interest rates. Since these increases were temporary, market participants expected them to be undone over time, which lead to considerable predictability of interest rates that dominated any variability of the term premium. In economies with floating exchange rates, by contrast, future changes in short-term interest rates were more difficult to predict, so that movements in the term-structure reflected largely variations in term-premia. As a consequence, the EH was rejected.

The second strand of the literature consists of papers using spectral methods to study the behaviour and determination of interest rates. A number of papers examine the spectral density functions for various interest rates with different maturities for differences in cyclical and seasonal movements. Fand (1966) finds spectral peaks at seasonal and cyclical periodicities in US short rates that are not present for long rates. Lagged long rates therefore turn out to be better predictors for future long rates than lagged short rates. Dobell and Sargent (1969) confirm this finding with Canadian interest rates. Using cross-spectral analysis they conclude that the short rate fluctuates with much greater amplitude than the long rate over all frequencies except 
the trend and that both rates show a surprisingly large degree of independence. Granger and Rees (1968) find that the coherence between UK interest rates of different maturities over long-run frequencies is large and declines in shorter frequency bands. For the US Sargent (1968) finds that the long rate leads the short rate and that the lead increases as shorter interest rates are considered. While these findings are indicative that the EH may not work well at the long end of the term structure, two other papers test the EH directly on US interest rates with frequency domain methods. Cargill and Meyer (1972) employ spectral methods to estimate the coefficients of a time-domain distributed lag model. They find that long rates respond quickly to changes in the short rate, but that the coefficient is significantly smaller than unity and the EH is thus rejected. In a related paper, Sargent (1972) also rejects constancy of the term premium using spectral methods. Recently, Donati and Donati (2007) decompose the yield curve and investigate the relation of its long-term, medium-term and short-term components with macroeconomic variables. Finally, Sarno et al. (2007) identify monetary policy shocks to the federal funds rate and investigate their propagation to other rates using a VAR in the spectral domain.

\section{Empirical work}

The EH has a number of implications for the joint behaviour of interest rates of different maturities. Testing typically exploits the fact that the spread between a long and a short interest rate should predict future changes in interest rates. In the literature, two different approaches to testing the $\mathrm{EH}$ are applied. One method to explore the empirical validity of the $\mathrm{EH}$ is to regress, essentially, the realised future path of the short-term interest rate on the term spread and test whether the coefficient on the term spread is unity. This approach is only feasible when testing the short end of the term structure, that is, when the maturity of the long rate is 3,6 or 12 months. Interestingly, tests using this approach frequently do not reject the EH. The alternative approach is to regress the change in long yields between $t$ and $t+1$ on the current spread. While theory suggests that, suitably normalised, the slope 
parameter should be unity, empirically it is generally estimated to be negative and significant. Since this test of the $\mathrm{EH}$ focuses on the behaviour of the long end of the yield curve, which may be relatively severely affected by the term premium, it is particularly interesting to focus on this implication of the $\mathrm{EH}$ when applying frequency domain techniques.

Our regression approach follows Hardouvelis (1994). Denoting the yield to maturity of a $N$-period coupon-paying bond by $R_{t}^{N}$ and the one-period interest rate by $r_{t}$, he obtains the following expression for the change in the long rate:

$$
R_{t+1}^{N-1}-R_{t}^{N}=\left(D_{N}-1\right)^{-1}\left\{\left(R_{t}^{N}-r_{t}\right)-\mathrm{E}_{t} \phi_{N, t}+\varepsilon_{t+1}\right\}
$$

where $D_{N}$ denotes the duration of a $N$-period bond (which is given by $D_{N} \approx\left(1-g^{N}\right) /(1-g), g=\left(1+\bar{R}^{N}\right)^{-1}$ and $\bar{R}^{N}$ denotes the sample mean of $\left.R_{t}^{N}\right), \phi_{N, t}$ is a term premium and $\varepsilon_{t+1}$ is a set of revisions of agents' expectations of future short rates and term premia (and is thus uncorrelated over time). Hardouvelis considers the regression:

$$
R_{t+1}^{N-1}-R_{t}^{N}=\alpha+\beta\left(D_{N}-1\right)^{-1}\left(R_{t}^{N}-r_{t}\right)+u_{t+1}
$$

and shows that the estimator, $\hat{\beta}$, can be written as

$$
\hat{\beta}=\frac{\operatorname{Var}\left(E_{t}\left(R_{t+1}^{N-1}-R_{t}^{N}\right)+\rho \operatorname{Var}\left(E_{t}\left(R_{t+1}^{N-1}-R_{t}^{N}\right)^{1 / 2} \operatorname{Var}\left(\phi_{N, t}\right)^{1 / 2}\right.\right.}{\operatorname{Var}\left(E_{t}\left(R_{t+1}^{N-1}-R_{t}^{N}\right)+\operatorname{Var}\left(\phi_{N, t}\right)+2 \rho \operatorname{Var}\left(E_{t}\left(R_{t+1}^{N-1}-R_{t}^{N}\right)^{1 / 2} \operatorname{Var}\left(\phi_{N, t}\right)^{1 / 2}\right.\right.}
$$

(see Gerlach and Smets, 1997). From this it follows that:

$$
\operatorname{plim} \beta=1-\frac{q(\rho+q)}{1+2 q \rho+q^{2}}
$$

where $q=\left(\operatorname{Var}\left(\mathrm{E}_{t} \phi_{N, t}\right) / \operatorname{Var}\left(\mathrm{E}_{t}\left(R_{t+1}^{N-1}-R_{t}^{N}\right)\right)\right)^{1 / 2} \quad$ and $\quad \rho=\operatorname{Corr}\left(\mathrm{E}_{t} \phi_{N, t}, \mathrm{E}_{t}\left(R_{t+1}^{N-1}-R_{t}^{N}\right)\right)$. Thus, if the term premium is constant over time, as is assumed by the $\mathrm{EH}, \beta$ should be estimated to be unity. However, equation (4) indicates that in the general case in which the term premium varies over time (so that the $\mathrm{EH}$ is false), plim $\beta$ can take any value as is clear from Figure 1 (which is copied from Hardouvelis, 1994, p. 271). 
Of course, depending on the precision of the estimates, the hypothesis that $\beta=0$ may not be rejected.

In this paper we test the $\mathrm{EH}$ at the long end of the term structure by estimating equation (2). In contrast to the existing literature, we perform the estimation in different frequency bands, using the band spectral regression (BSR) procedure of Engle (1974). The reason for doing so is straightforward. Following Hardouvelis (1994, p. 274), we can obtain an expression equivalent to equation (1) for the spread between long and short interest rates as function of the future path of short rates (relative to the current short rate) and a term premium:

$$
\left(\sum_{i=0}^{N-1} w_{i} \mathrm{E}_{t} r_{t+i}-r_{t}\right)+\mathrm{E}_{t} \theta_{t} \equiv R_{t}^{N}-r_{t}
$$

where $w_{i}=g^{i} / D_{N}$ and $\mathrm{E}_{t} \theta_{t}=\sum_{i=0}^{N-1} w_{i} \mathrm{E}_{t} \phi_{N-1, t+i}$.

The rationale for testing the $\mathrm{EH}$ using BSR arises from the fact that the relative importance of the two terms on the left hand side of equation (5) (or, equivalently, equation (1)) may vary across frequency bands. To see this, suppose that the term premium is white noise, which implies, importantly, that its variance is the same in all frequency bands. Suppose furthermore that central banks do not react to very short-term or high-frequency phenomena - perhaps because the lags by which monetary policy affects the economy are too long for policy to be able to stabilise the economy - but only to shocks that have more persistent economic effects. If so, interest rate expectations would contribute little to movements in the term structure at high frequencies, leaving term premia to be the dominant factor driving and the $\mathrm{EH}$ to be rejected. At somewhat lower frequencies in which interest rate expectations vary more as monetary policy reacts to shifts in economic conditions, it is possible that the $\mathrm{EH}$ fits the data better. At a still lower frequency band, variation in the interest rate expectations may again be weaker, leaving the $\mathrm{EH}$ to be rejected. 


\section{The data}

We use monthly interest rate data for the US, expressed in percentages, and consider three different maturities for the short-term interest rate: the 1-month London interbank bid (LIBID) rate for US dollars, the 3-month and the 6-month US treasurybill rates. For the long-term interest rates we use US government bond rates for six different maturities of $1,2,3,5,7$ and 10 years. Interest rates are monthly averages and, except for the 1-month LIBID rate that is from Bloombergs, are obtained from the website of the Federal Reserve Bank of St. Louis. Following Hardouvelis (1994), the short rates are transformed to bond equivalent yields, $r$, from discount yields, $y$, according to the formula $r=(365 y / 100) /(360-d y / 100)$, where $d$ denotes days to maturity, which are 30 for the 1-month rate, 91 for the 3-month rate and 182 for the 6 month rate.

Since we do not want to deal with the disinflation period in the early eighties when interest rates were unusually volatile, we start our sample in September 1987, that is, at the time Alan Greenspan was appointed Chairman of the Board of Governors of the Federal Reserve System. The sample period ends in February 2007. Figure 2 shows the data. It is apparent that all interest rates share the same movements over time, though the short rates tend to be more volatile than the longer maturities. For the largest part of the sample the slope of the yield curve was positive, with some short exceptions around 2000 and at the end of the sample.

Next we consider the left-hand and the right-hand side variables in the regression equation (2). Figure 3 shows changes in the long rates of six different maturities $(1,2$, 3, 5, 7 and 10 years), together with the spreads between these long rates and short rates of 1,3 or 6 months maturity. While the change in the long rates is clearly stationary, it is much less clear whether the term spreads are. In fact, term spreads involving the longest maturities show much less mean reversion and formal (unreported) tests of stationarity often reject. 
This pattern carries over to the frequency domain properties of the data. Figure 4 shows the spectra for the changes in the long rate in the first panel and the three different term spreads in the other three panels. While differencing the long rate removes most of the power around the zero frequency and flattens the spectrum, the term spreads are persistent as evidenced by the high spectral density near the origin, and thus display what Granger (1966) refers to as the typical spectral shape of a nonstationary time series. Figure 4 shows that the change in the one-year interest rate has the most power at the lowest frequencies. Furthermore, the spread between the 1-month and 1-year rate appears to have a greater spectral density at the origin than the other term spreads. This suggests that the EH may fare better in the case in which the short rate is the 1-month rate, and the long rate is the 1 year rate.

Importantly, Figure 4 shows that the spectral densities of the series are quite similar irrespectively of which change in the long rate, or which term spread, is considered. However, the spectral densities of the changes in the long rates do not match closely with the spectral densities of the term spreads. Moreover, the closeness of the match appears to vary between frequencies. This suggests that estimates of equation (2) will vary across frequency bands. Furthermore, they are likely to be better in the frequency band between six months and four years, which corresponds to frequencies between $0.33 \pi$ and $0.04 \pi$, where both the spreads and changes of interest rates for at least some maturities have considerable power. ${ }^{1}$

We next present a brief exposition of the empirical method used before we discuss the results.

\section{Empirical methods and results}

Band spectrum regression (BSR) was first proposed by Engle (1974), who shows that if $y=x \beta+\varepsilon$ is a valid regression model in the time domain, it can be transformed

1 Measuring frequency, $\omega$, in fractions of $\pi$, periodicity in months is given by $2 \pi / \omega$. Thus, a frequency of $\omega=0.1 \pi$ corresponds to a periodicity of 20 months. 
into the frequency domain by applying a Fourier transformation to both the dependent and the independent variables. Denoting the transformed variables as $\tilde{x}$ and $\tilde{y}$, the regression in the frequency domain is $\tilde{y}=\tilde{x} \beta+\widetilde{\varepsilon} .^{2}$ The estimator, $\hat{\beta}$, then can be written as:

(6) $\hat{\beta}=\left[\sum_{k=0}^{T-1} \hat{f}_{x x}\left(\omega_{k}\right)\right]^{-1} \sum_{k=0}^{T-1} \hat{f}_{x y}\left(\omega_{k}\right)$,

where $T$ is the sample size, $\hat{f}_{x x}(\omega)$ is the periodogram of the series in $x$ at each frequency $\omega$ and $\hat{f}_{x y}(\omega)$ is a vector of cross periodograms. ${ }^{3}$ The benefit of transferring the regression model into the frequency domain is that it permits a test of the hypothesis that a specific model applies to some but not to all frequencies. In this case we premultiply the regression model by a $T \times T$ matrix $A$ with unity on the diagonal for each included frequency and zero elsewhere,

$$
A \tilde{y}=A \tilde{x} \beta+A \tilde{\varepsilon}, \text { where } E(A \tilde{\varepsilon})(A \tilde{\varepsilon})^{*}=\sigma^{2} A
$$

with an asterisk, "*", denoting the complex conjugate of the transposed matrix. Thus, to compute $\hat{\beta}$ we sum over a frequency band instead of the full range of frequencies as in equation (6). ${ }^{4}$ If equation (6) is estimated only for a subset of frequencies, but is true for all frequencies, the estimator is consistent but inefficient as it does not use all available information. By contrast, if the model applies only to a specific frequency band, using information from all frequencies might obscure the relationship between the variables.

2 The transformation to the frequency domain does not affect the standard regression results.

3 Since the estimator of $\beta$ averages over periodograms, there is no need to smooth these as is necessary when estimating the spectrum.

4 Though the cross-periodograms in equation (5) are complex, $\hat{\beta}$ will be real if the $k^{\text {th }}$ frequency component is included along with the $T-k^{\text {th }}$ component. 


\subsection{Regression results}

Next we estimate equation (2), focusing on the intermediate (6 to 48 month) frequency band in which we believe that the EH may be accepted by the data. Our results are presented in Table 1. Before interpreting the results, we explain how the table is constructed. The third column shows the estimate of $\beta$ and, between parentheses, its standard error, while the fourth column presents the $t$-statistics from tests of the hypotheses that $\beta$ is significantly different from zero and from unity, respectively. If $\beta$ is significantly different from zero but insignificantly different from unity, we interpret this as evidence in favour of the EH. For comparison, columns five and six present $\beta$ and the $t$-statistics from the same tests when all frequencies are used, which corresponds to estimating equation (2) using OLS.

The third column of Table 1 shows that the point estimate of $\beta$ exceeds unity for all regressions. By contrast, the OLS estimates are close to unity only for the regression involving maturities of up to two years and confirm the results in the literature, in which the long rate is frequently taken to be a 10-year rate, that generally obtains a negative point estimate. Moreover, the coefficient estimates in the third column increase when longer maturities are used as the dependent variable. In only one of 18 regressions - when the short rate is 3 months and the long rate is 3 years - do we not reject (at the $5 \%$ level of significance) the hypothesis that $\beta$ equals zero, though the $t$ value of 1.94 is marginally below the critical value. By contrast, on only two occasions do we obtain a significant slope parameter in the OLS regressions.

Furthermore, in ten cases are we unable to reject the hypothesis that $\beta$ equals unity when we restrict attention to the 6-to-48-months frequency band. By contrast, we only do so on two occasions when the OLS estimates are used. In sum, the regressions are much more supportive of the $\mathrm{EH}$ when we focus attention on the 6month to 4-year frequency band than when all frequencies are used.

To better understand the common rejections of the $\mathrm{EH}$ when all frequencies are included (that is, when OLS is used), Figure 5 shows the coefficient estimates for 
different maturities of the long rate using the term spreads relative to the 1-month rate and for three different frequency bands - a low-frequency band comprising fluctuations with a periodicity of more than 4 years, the intermediate-frequency band comprising fluctuations of between 6 months and 4 years we discussed above, and a high-frequency band containing fluctuations with a periodicity of less than 6 months. ${ }^{5}$ The different behaviour of $\beta$ across frequency bands is immediately apparent. First, the coefficient is small at high frequencies and becomes increasingly negative when the dependent variable is computed using longer maturities. ${ }^{6}$ This illustrates why conventional methods often find negative point estimates for $\beta$. Second, the estimate of $\beta$ is positive in the intermediate band, though it generally exceeds unity. Third, in the low-frequency band $\beta$ is positive for short maturities of the dependent variable such as 1 to 3 years, if a term spread relative to the 1-month and 3-month rate is used, and 1 year if the term spread is defined using the 6-month rate. We can see that with OLS (which averages across all frequency bands) the EH is less likely to be rejected when it is tested on short-term interest rates than at the long end of the yield curve, mainly because of the large negative coefficients that are obtained for the high-frequency band when using long-term interest rates.

Engle (1974) shows that a conventional F-test can be used to test for equality of the parameters across frequency bands. Performing such a test, we find, not surprisingly, that the equality of $\beta$ across frequency bands is strongly rejected for all 18 pairs of long rates and term spreads with test statistics between $F_{1,230}=20.47$ to $F_{1,230}=43.38$, which all far exceed the critical value at the $5 \%$ significance level of 3.89 . This is evidence against the hypothesis that $\beta$ is the same in frequency bands as the OLS estimates implicitly assume.

5 Defining the term spreads relative to the 3-month and 6-month rates yield very similar results and we therefore do not show them in the figure. The coefficient estimates for the high and the lowfrequency bands are also available in Table A1 in the appendix.

6 Equally, the coefficients become increasingly negative when the term spread is computed using longer maturities. 


\subsection{Monetary policy and the relative importance of the term premium}

Next we seek to explain the variation in the estimates of $\beta$ across frequency bands. We hypothesise that the importance of the term premium relative to the expected change in the long-term interest rate in accounting for movements in the term structure varies across frequency bands (rather than over time, as in Mankiw and Miron (1986), or across countries, as in Gerlach and Smets $(1997,1998))$.

Dividing the numerator and the denominator of the right-hand side in equation (3) by $\operatorname{Var}\left(R_{t+1}^{N-1}-R_{t}^{N}\right)$, the estimated slope coefficient $\hat{\beta}$ can be written as

$$
\hat{\beta}=\frac{R^{2}+\rho R \theta}{R^{2}+2 \rho R \theta+\theta^{2}},
$$

where $\rho$ is defined as in equation (4), $R^{2}$ denotes the ratio of the expected variance of the change in the long-term interest rate to its actual variance, $R^{2}=\operatorname{Var}\left(\mathrm{E}_{t}\left(R_{t+1}^{N-1}-R_{t}^{N}\right)\right) / \operatorname{Var}\left(R_{t+1}^{N-1}-R_{t}^{N}\right)$, and $\theta^{2}$ the ratio of the variance of the term premium to the variance of changes in the long rate, $\theta^{2}=\operatorname{Var}\left(\phi_{N, t}\right) / \operatorname{Var}\left(R_{t+1}^{N-1}-R_{t}^{N}\right)$. $R^{2}$ thus can be interpreted as a measure of the predictability of the change in the long interest rate, whereas $\theta^{2}$ measures the relative importance of the term premium.

To disentangle the influence of expectation errors and time-varying term premia on the performance of the EH in different frequency bands we follow Gerlach and Smets $(1997,1998)$ and estimate an auxiliary regression for changes in the long rate. This gives us an estimate of $R^{2}$ which we use together with the estimates of $\beta$ to fit equation (8). All deviations from the EH are then interpreted as arising from the time-varying risk premium. This assumption, however, might be incorrect. Recent research by Piazzesi and Schneider (2008) and by Kim and Orphanides (2005) indicates that survey expectations of long rates deviate substantially from the expected long rate implied by the $\mathrm{EH}$

To measure the predictability of the change in the long interest rate we follow Hardouvelis (1994, p. 272, equation 4c.2) and regress the change in the long rate for 
each frequency band on a constant, the lagged term spread and the lagged change in the short interest rate.

$$
R_{t+1}^{N-1}-R_{t}^{N}=\gamma_{0}+\gamma_{1}\left(R_{t}^{N}-r_{t}\right)+\gamma_{2}\left(r_{t}-r_{t-1}\right)+\varepsilon_{t}
$$

In contrast to Hardouvelis, we do not include further lags in equation (9) since the filtering the variables in the intermediate and low frequency-band regressions would lead to multicollinearity among the regressors. We then use the $R^{2}$ from this regression, together with the estimated $\beta$ coefficients from equation (2), to obtain estimates of $\rho$ and $\theta$. Assuming that $\theta$ and $\rho$ are constant across maturities, we have 18 observations for $\hat{\beta}$ and $R^{2}$ for each of the three frequency bands, which we use to estimate the following regression:

$$
\hat{\beta}_{i}=\frac{R_{i}^{2}+\alpha_{1} R_{i}}{R_{i}^{2}+2 \alpha_{1} R_{i}+\alpha_{2}}+\xi_{i}, i=1,2,3,
$$

where $\alpha_{1}=\rho \theta$ and $\alpha_{2}=\theta^{2}$. The resulting coefficient estimates are shown in Table 2 . All coefficients are of plausible sign and magnitude. The coefficient $\alpha_{2}$ measures the relative importance of the term premium in explaining the change in the long rate. It turns out that the estimate of $\alpha_{2}$ is lowest in the intermediate frequency band, explaining only $5 \%$ of the variability in the long rate, whereas the variance of the term premium accounts for 35 percent of the variability of the long rate in the highfrequency band. At low frequencies almost all variation in the long rate seems to be due to variability of the term premium.

These estimates, however, do not say anything about the absolute size of the risk premium at different frequencies. To see this, suppose, as we have so far, that the risk premium is white noise so that its variance is constant across frequency bands. In this case the coefficient $\theta$ is determined exclusively by $\operatorname{Var}\left(R_{t+1}^{N-1}-R_{t}^{N}\right)$. In our data the variance of the change in the long-term rate is indeed highest in the intermediate band, which suffices to produce the results in Table 2. Thus, the fact that we are frequently unable to reject the $\mathrm{EH}$ in the intermediate frequency band may results 
largely from the fact that monetary policy is relatively easily predictable in this frequency band. In turn, this predictability may arise as a consequence of the Federal Reserve's attempts to stabilize the economy by responding to the state of the business cycle since it is clear that interest rates will rise after recessions and fall after business cycles expansions.

The estimate of $\alpha_{1}$ is negative for all frequency bands, which corresponds to results found in the literature. ${ }^{7}$ The correlation of the term premium and the expected change in the long rate is close to minus unity and decreases slightly in the lower frequency band. Of course, these results may be subject to generated regressor bias, since both the dependent and the independent variable stem from first-step regressions, and thus have to be treated with caution.

We finally compare our estimates of $\beta$ with plim $\beta$ in equation (4) using our estimates of $\rho$ and $\theta$. Recall from Figure 1 that $\hat{\beta}$ will only be unity if the term premium is constant, i.e. $q=0$. Figure 6 shows the estimated $\beta$ coefficients from all three frequency bands as a function of the relative variability of the term premium. ${ }^{8}$ The symbols represent the individual estimates of $\beta$, while the solid line shows the theoretical relation, assuming a correlation between the expected risk premium and the expected change in the long rate of $-0.99 .{ }^{9}$ The results are broadly consistent with the theoretical relation. The estimates from the high frequency band are shown as squares and the estimates from the low-frequency band are marked by a triangle. They all lie around $q=1$. While the estimates for the low-frequency band cluster around the theoretical relation, the $\beta$ coefficients for the high frequency band are much smaller than the theoretical relation. One reason for this can be that the use of

7 See, e.g., Mankiw and Miron (1986).

8 We obtain $q$ by dividing $\theta$ by the $R^{2}$ from the forecasting regression.

9 This is the value Hardouvelis (1994) reports for the US. McCallum (2005) shows that if the central bank reacts systematically to the term spread when setting short-term interest rates, such a negative correlation can arise. 
monthly data biases results in the high-frequency band because the smallest cycle we can distinguish is a cycle of two months (the so-called Nyquist frequency) whereas interest rates and expectations are formed at a much higher frequency. The estimates for the intermediate band are marked by a diamond and lie below $q=1$ in the positive part of the graph. We conclude that the relative variability of the term premium is able to explain the different success of the $\mathrm{EH}$ across frequency bands. In particular, the change in the long rate seems to be more variable and more easily predictable at business cycle frequencies of 6 to 48 months, making rejections of the EH less likely in this frequency band.

\section{Conclusions}

In this paper we test the $\mathrm{EH}$ of the term structure of interest rates in US data, using spectral techniques that allow us to consider different frequency bands. Strikingly, our estimates show that the slope coefficient on the term spread changes sign across frequency bands. At high frequencies, defined as fluctuations with a periodicity of less than 6 months, we find a negative relation between the term spread and the change in the long-term interest rate. In an intermediate frequency band, corresponding to a time horizon of 6 months to 4 years, we find a positive reaction of the future change in the long rate to the term spread, whereas at low frequencies beyond 4 years the relation is positive for short maturities and negative for longer maturities. We conjecture that the variance of the term premium relative to expected changes in the long rate varies across frequency bands and find some support in the data for this hypothesis. While our approach does not allow us to isolate the absolute variability the term premium, we interpret our results as indicating that the predictability of interest rates varies across frequency bands as a consequence of the conduct of monetary policy.

These findings have two implications for monetary policy makers and central bank watchers. First, to the extent that the $\mathrm{EH}$ is rejected because market participants can not form expectations of future interest rates, high levels of transparency in setting 
and conducting monetary policy seem desirable. The reason for this is simple: Bonds and other securities will experience relatively large and undesirable valuation gains and losses in response to unpredicted changes in monetary policy. Greater transparency makes monetary policy more predictable and reduces the severity of such valuation changes.

Second, since the rejection of the EH appears largely due to high-frequency fluctuations in the data and the EH seems to do a better job accounting for interest rates changes in intermediate frequency bands, the slope of the yield curve can be used as a measure of market participants' expectations of changes in monetary policy. However, short-run or high frequency fluctuations in the term structure of interest rates do not seem to contain much information about future interest rates and should be disregarded. 


\section{Appendix}

Table A1. Estimates of equation (2) in the 2-to-6 months and 48-to- $\infty$ months frequency band.

\begin{tabular}{llcccc}
\hline Change in & $\begin{array}{l}\text { Term } \\
\text { spread }\end{array}$ & $\begin{array}{c}\beta(2 \text {-to-6 } \\
\text { month band })\end{array}$ & $\begin{array}{c}\text { Standard } \\
\text { error }\end{array}$ & $\begin{array}{c}\beta \text { (48-to- } \infty \\
\text { month band })\end{array}$ & $\begin{array}{c}\text { Standard } \\
\text { error }\end{array}$ \\
\hline 1-year rate & 1 month & $-3.991^{*}$ & 0.730 & $1.110^{*}$ & 0.341 \\
1-year rate & 3 months & $-11.529^{*}$ & 1.440 & $4.321^{*}$ & 0.490 \\
1-year rate & 6 months & $-13.929^{*}$ & 3.402 & $3.928^{*}$ & 1.059 \\
2-year rate & 1 month & $-9.302^{*}$ & 1.581 & 0.502 & 0.426 \\
2-year rate & 3 months & $-21.181^{*}$ & 2.040 & 1.233 & 0.705 \\
2-year rate & 6 months & $-23.399^{*}$ & 3.537 & -0.173 & 0.749 \\
3-year rate & 1 month & $-14.022^{*}$ & 2.284 & 0.115 & 0.416 \\
3-year rate & 3 months & $-29.077^{*}$ & 2.938 & 0.221 & 0.594 \\
3-year rate & 6 months & $-31.194^{*}$ & 4.554 & -0.578 & 0.590 \\
5-year rate & 1 month & $-20.735^{*}$ & 3.604 & -0.341 & 0.331 \\
5-year rate & 3 months & $-42.349^{*}$ & 4.369 & -0.509 & 0.415 \\
5-year rate & 6 months & $-43.513^{*}$ & 6.079 & $-0.827^{*}$ & 0.403 \\
7-year rate & 1 month & $-26.579^{*}$ & 4.565 & -0.490 & 0.313 \\
7-year rate & 3 months & $-50.631^{*}$ & 5.977 & -0.696 & 0.378 \\
7-year rate & 6 months & $-49.789^{*}$ & 7.961 & $-0.913^{*}$ & 0.366 \\
10-year rate & 1 month & $-33.529^{*}$ & 5.956 & -0.455 & 0.285 \\
10-year rate & 3 months & $-62.868^{*}$ & 7.314 & -0.643 & 0.335 \\
10-year rate & 6 months & $-62.138^{*}$ & 9.508 & $-0.785^{*}$ & 0.326 \\
\hline
\end{tabular}

Note: The dependent variable is indicated in column 1. The sample period is 1987M9 to 2007M2.

Standard errors are given in parentheses. An asterisk indicates significance at the $5 \%$ level. 


\section{References}

Campbell, John Y. and Robert J. Shiller (1987), "Cointegration and Tests of Present Value Models," Journal of Political Economy, 95, 1062-1088.

Campbell, John Y. and Robert J. Shiller (1991), "Yield Spreads and Interest Rate Movements: A Bird's Eye View," Review of Economic Studies, 58, 495-514.

Cargill, Thomas F. and Robert A. Meyer (1972), "A Spectral Approach to Estimating the Distributed Lag Relationship between Long and Short Term Interest Rates," International Economic Review, 13, 223-238.

Dobell, Rodney and Thomas J. Sargent (1969), "The Term Structure of Interest Rates in Canada," Canadian Journal of Economics, 2, 65-77.

Donati, Paola and Francesco Donati (2007), "What Moves the Yield Curve? Inflation and Money at Different Horizons," European Central Bank mimeo.

Engle, Robert F. (1974), "Band Spectrum Regression," International Economic Review, $15,1-11$.

Fand, David I. (1966), "A Time-Series Analysis of the "Bills-Only" Theory of Interest Rates," Review of Economics and Statistics, 48, 361-371.

Gerlach, Stefan and Frank Smets (1997), "The Term Structure of Euro-Rates: Some Evidence in Support of the Expectations Hypothesis," Journal of International Money and Finance, 16, 305-321.

Gerlach, Stefan and Frank Smets (1998), "Exchange Rate Regimes and the Expectations Hypothesis of the Term Structure," in: Ignazio Angeloni and Riccardo Rovelli (ed.), Monetary Policy and Interest Rates, Macmillan, London, 11-35.

Granger, Clive W. J. and H. J. B. Rees (1968), "Spectral Analysis of the Term Structure of Interest Rates," Review of Economic Studies, 35, 67-76.

Hardouvelis, Gikas A. (1994), "The Term Structure Spread and Future Changes in Long and Short Rates in the G7 Countries: Is there a Puzzle?," Journal of Monetary Economics, 33, 255-283.

Kim, Don H. and Athanasios Orphanides (2005), "Term Structure Estimation with Survey Data on Interest Rate Forecasts," Federal Reserve Board Finance and Economics Discussion Series No. 48.

Mankiw, N. Gregory and Jeffrey A. Miron (1986), "The Changing Behavior of the Term Structure of Interest Rates," Quarterly Journal of Economics, 101, 211-228.

McCallum, Bennett T. (2005), "Monetary Policy and the Term Structure of Interest Rates," Federal Reserve Bank of Richmond Economic Quarterly, 91, 1-21.

Piazzesi, Monika and Martin Schneider (2008), "Bond Positions, Expectations, and the Yield Curve," Paper presented at the UFSP Conference on "Macroeconomics and Finance", University of Zurich, March 5, 2008 
Sargent, Thomas J. (1968), "Interest Rates in the Nineteen-Fifties," Review of Economics and Statistics, 50, 164-172.

Sargent, Thomas J. (1972), "Rational Expectations and the Term Structure of Interest Rates," Journal of Money, Credit, and Banking, 4, 74-97. 
Table 1. Estimates of equation (2) in the 6 to 48 month frequency band and with OLS.

\begin{tabular}{|c|c|c|c|c|c|}
\hline Change in & Term spread & $\beta$ & Tstat $(\beta=0 / 1)$ & $\beta O L S$ & Tstat $(\beta=0 / 1)$ \\
\hline \multirow[t]{2}{*}{ 1-year rate } & 1 month & 1.845 & $3.890^{*}$ & 0.723 & 1.315 \\
\hline & & $(0.474)$ & 1.781 & $(0.550)$ & -0.504 \\
\hline \multirow[t]{2}{*}{ 1-year rate } & 3 months & 1.862 & $2.517^{*}$ & 1.846 & $2.262^{*}$ \\
\hline & & $(0.740)$ & 1.165 & $(0.816)$ & 1.037 \\
\hline \multirow[t]{2}{*}{ 1-year rate } & 6 months & 3.689 & $3.341^{*}$ & 2.726 & $2.165^{*}$ \\
\hline & & $(1.104)$ & $2.435^{*}$ & (1.259) & 1.371 \\
\hline \multirow[t]{2}{*}{ 2-year rate } & 1 month & 2.218 & $2.982^{*}$ & 0.506 & 0.628 \\
\hline & & $(0.744)$ & 1.637 & $(0.806)$ & -0.613 \\
\hline \multirow[t]{2}{*}{ 2-year rate } & 3 months & 2.043 & $2.171^{*}$ & 0.925 & 0.952 \\
\hline & & $(0.941)$ & 1.108 & (0.917) & -0.078 \\
\hline \multirow[t]{2}{*}{ 2-year rate } & 6 months & 3.227 & $2.812^{*}$ & 0.905 & 0.775 \\
\hline & & (1.147) & 1.941 & (1.168) & -0.081 \\
\hline \multirow[t]{2}{*}{ 3-year rate } & 1 month & 2.721 & $2.641^{*}$ & 0.284 & 0.300 \\
\hline & & $(1.031)$ & 1.670 & $(0.949)$ & -0.754 \\
\hline \multirow[t]{2}{*}{ 3-year rate } & 3 months & 2.424 & 1.937 & 0.482 & 0.429 \\
\hline & & $(1.251)$ & 1.138 & (1.123) & -0.461 \\
\hline \multirow[t]{2}{*}{ 3-year rate } & 6 months & 3.733 & $2.525^{*}$ & 0.442 & 0.353 \\
\hline & & $(1.478)$ & 1.849 & (1.251) & -0.446 \\
\hline \multirow[t]{2}{*}{ 5-year rate } & 1 month & 3.811 & $2.784^{*}$ & -0.001 & -0.001 \\
\hline & & (1.369) & $2.053^{*}$ & $(1.026)$ & -0.976 \\
\hline \multirow[t]{2}{*}{ 5-year rate } & 3 months & 3.374 & $2.080^{*}$ & 0.004 & 0.004 \\
\hline & & (1.622) & 1.464 & (1.179) & -0.844 \\
\hline \multirow[t]{2}{*}{ 5-year rate } & 6 months & 5.091 & $2.783^{*}$ & 0.038 & 0.031 \\
\hline & & $(1.829)$ & $2.236^{*}$ & (1.233) & -0.780 \\
\hline \multirow[t]{2}{*}{ 7-year rate } & 1 month & 5.124 & $3.166^{*}$ & -0.087 & -0.081 \\
\hline & & (1.618) & $2.548^{*}$ & (1.063) & -1.022 \\
\hline \multirow[t]{2}{*}{ 7-year rate } & 3 months & 4.359 & $2.279^{*}$ & -0.144 & -0.119 \\
\hline & & (1.913) & 1.756 & (1.204) & -0.950 \\
\hline \multirow[t]{2}{*}{ 7-year rate } & 6 months & 6.534 & $3.091^{*}$ & -0.032 & -0.026 \\
\hline & & (2.114) & $2.618^{*}$ & $(1.231)$ & -0.838 \\
\hline \multirow[t]{2}{*}{ 10-year rate } & 1 month & 6.575 & $3.332^{*}$ & -0.080 & -0.072 \\
\hline & & (1.973) & $2.825^{*}$ & (1.119) & -0.965 \\
\hline \multirow[t]{2}{*}{10 -year rate } & 3 months & 5.444 & $2.348^{*}$ & -0.195 & -0.155 \\
\hline & & (2.319) & 1.917 & (1.257) & -0.951 \\
\hline \multirow[t]{2}{*}{10 -year rate } & 6 months & 8.023 & $3.166^{*}$ & -0.042 & -0.033 \\
\hline & & $(2.534)$ & $2.772^{*}$ & $(1.270)$ & -0.821 \\
\hline
\end{tabular}

Note: The dependent variable is indicated in column 1 . The first entry in columns 3 and 5 tests the hypothesis $\beta=0$, the second $\beta=1$. The sample period is 1987M9 to 2007M2. Standard errors are given in parentheses. An asterisk indicates significance at the $5 \%$ level. 
Table 2. Estimates of predictability

\begin{tabular}{lccc}
\hline Coefficient & $\begin{array}{c}\text { Low-frequency } \\
\text { band }\end{array}$ & $\begin{array}{c}\text { Intermediate-frequency } \\
\text { band }\end{array}$ & $\begin{array}{c}\text { High-frequency } \\
\text { band }\end{array}$ \\
\hline$\alpha_{1}$ & -0.594 & -0.233 & -0.951 \\
& $(0.003)$ & $(0.008)$ & $(0.011)$ \\
$\alpha_{2}$ & 0.352 & 0.055 & 0.945 \\
& $(0.004)$ & $(0.003)$ & $(0.031)$ \\
\hline Uncentered R ${ }^{2}$ & 0.624 & 0.781 & 0.279 \\
Durbin Watson & 1.704 & 1.508 & 1.092 \\
\hline$\theta$ & 0.593 & 0.234 & 0.972 \\
$\rho$ & -0.999 & -0.994 & -0.978 \\
\hline
\end{tabular}

Note: Estimate of equation (8) with 18 observations. Estimated by nonlinear least squares (GaussNewton) with robust standard errors. 
Figure 1. The regression slope as a function of the relative variability of the risk premium.

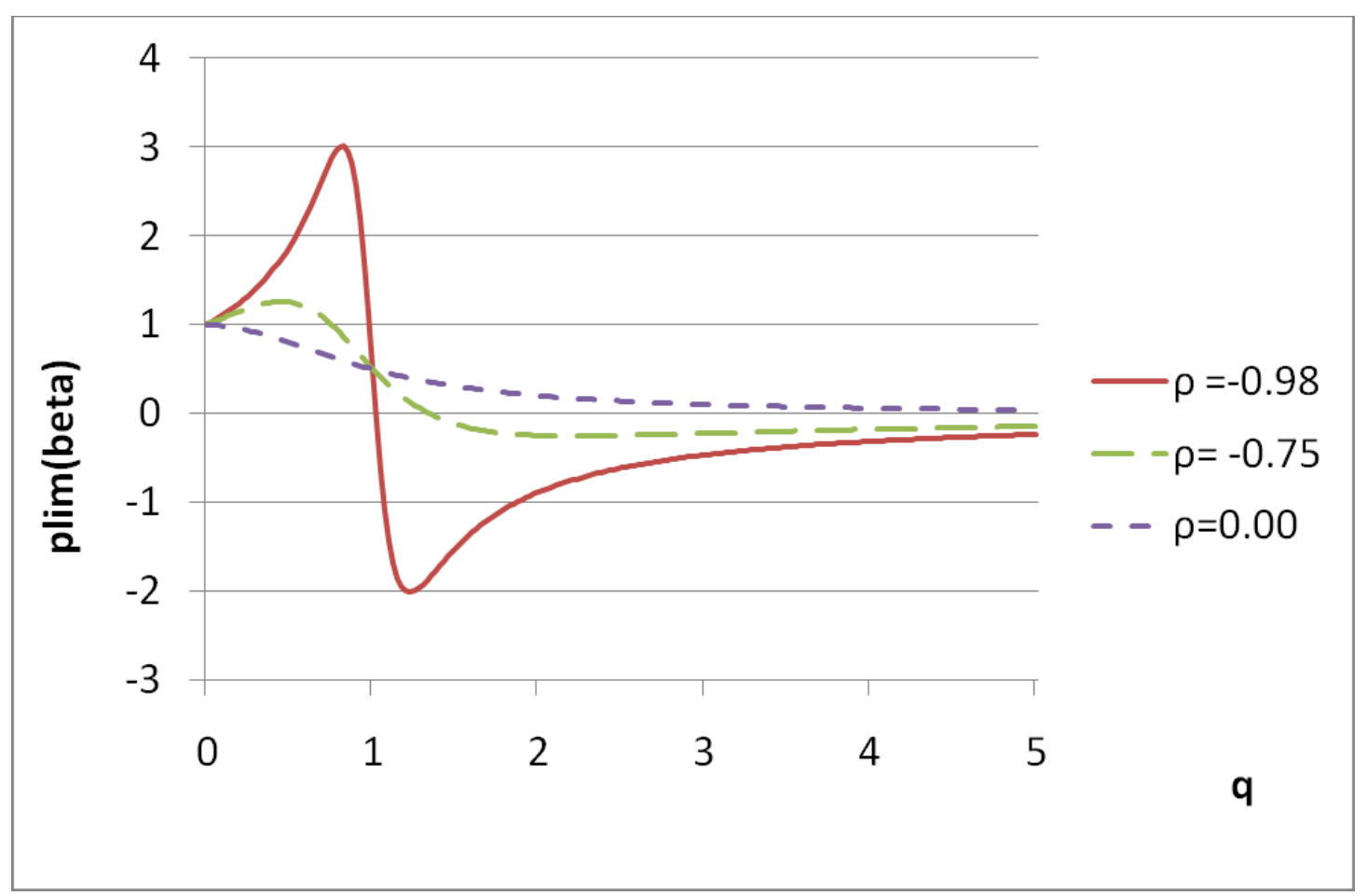

Note: $\operatorname{plim}(\beta)=1-q(p+q) /\left(1+2 p q+q^{2}\right)$, where $\beta$ is the slope coefficient of the regression equation (2), $q$ denotes the relative variability of the risk premium and $\varrho$ is the correlation between the expected risk premium and the expected change in the long rate, see Hardouvelis (1994).

Figure 2. Data

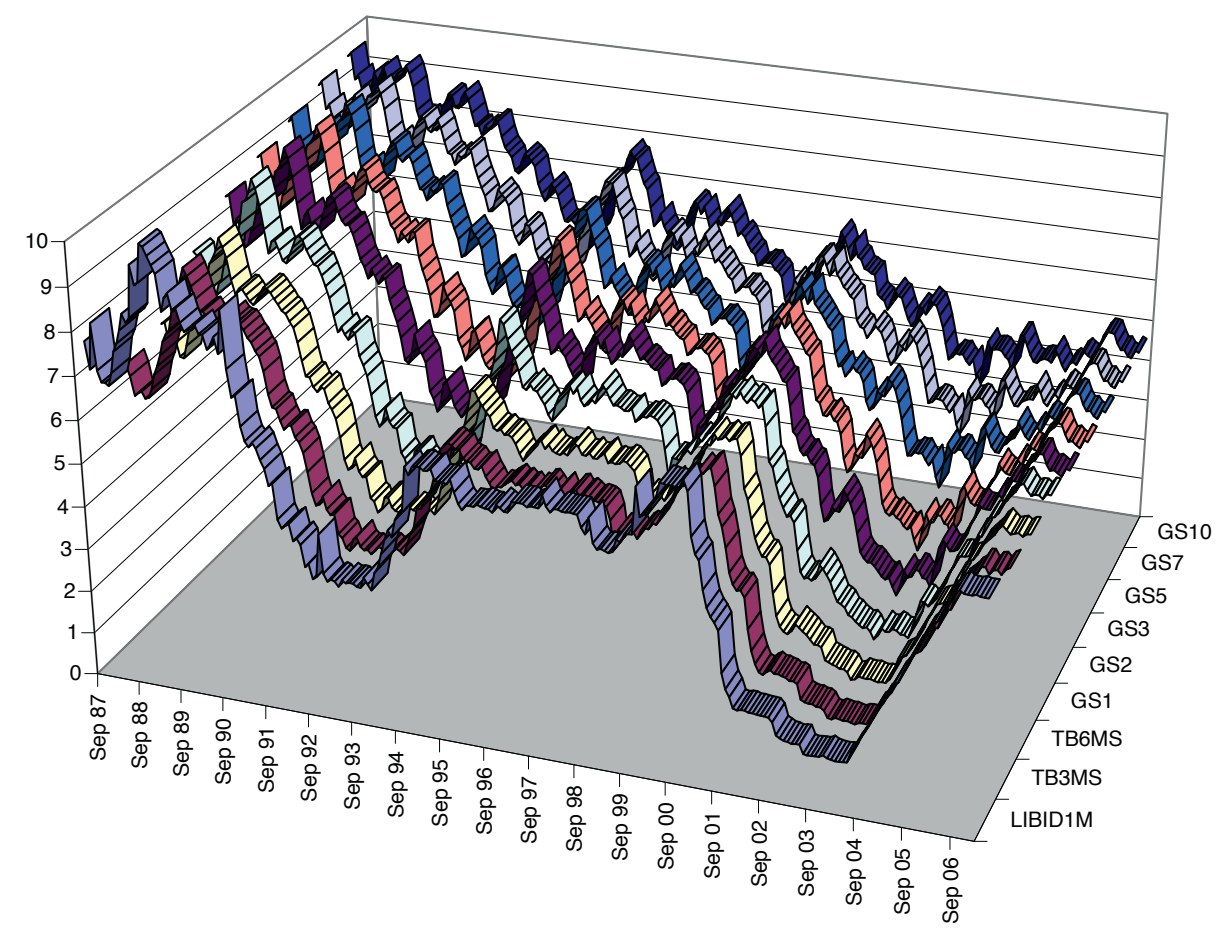



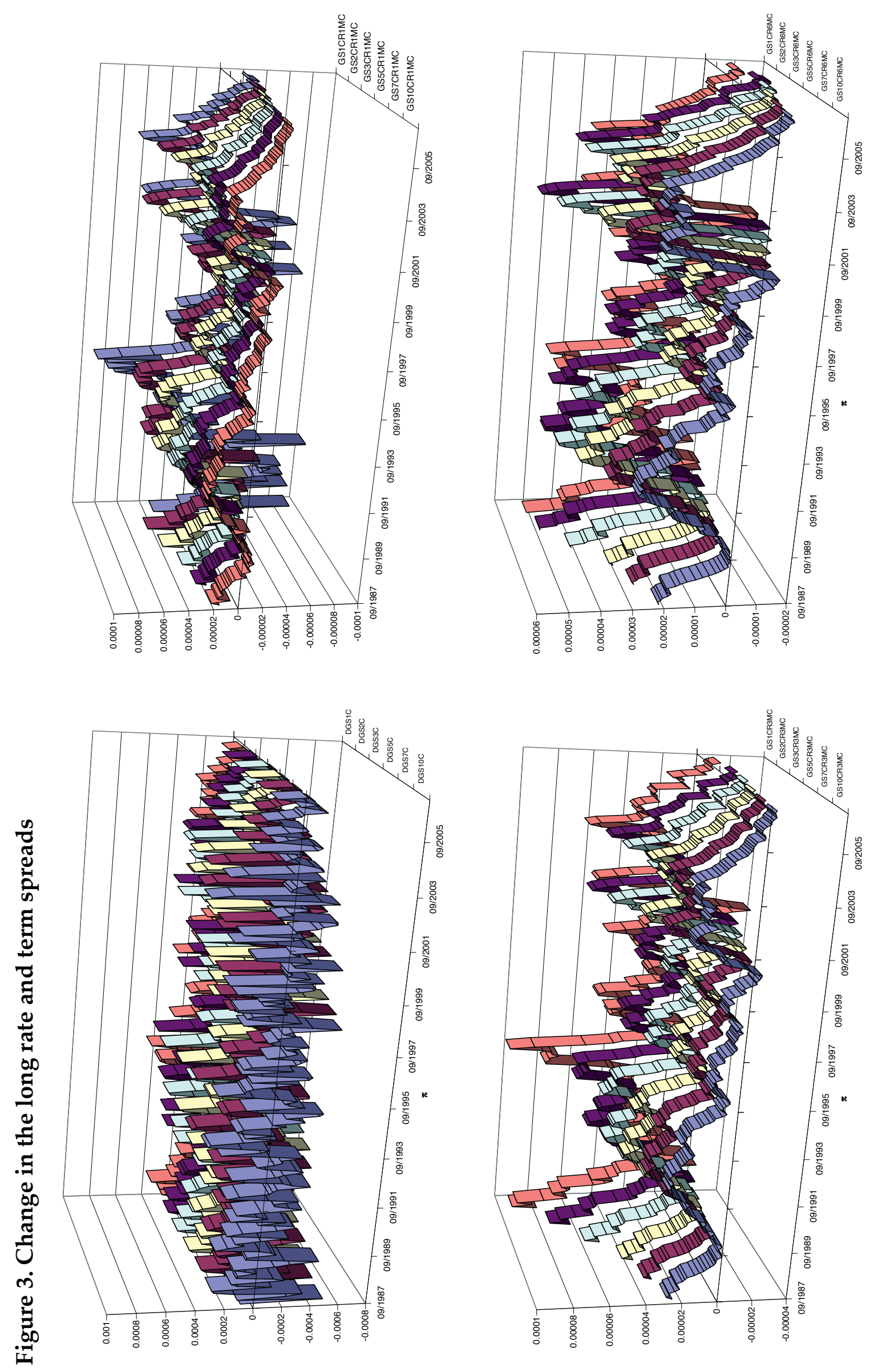

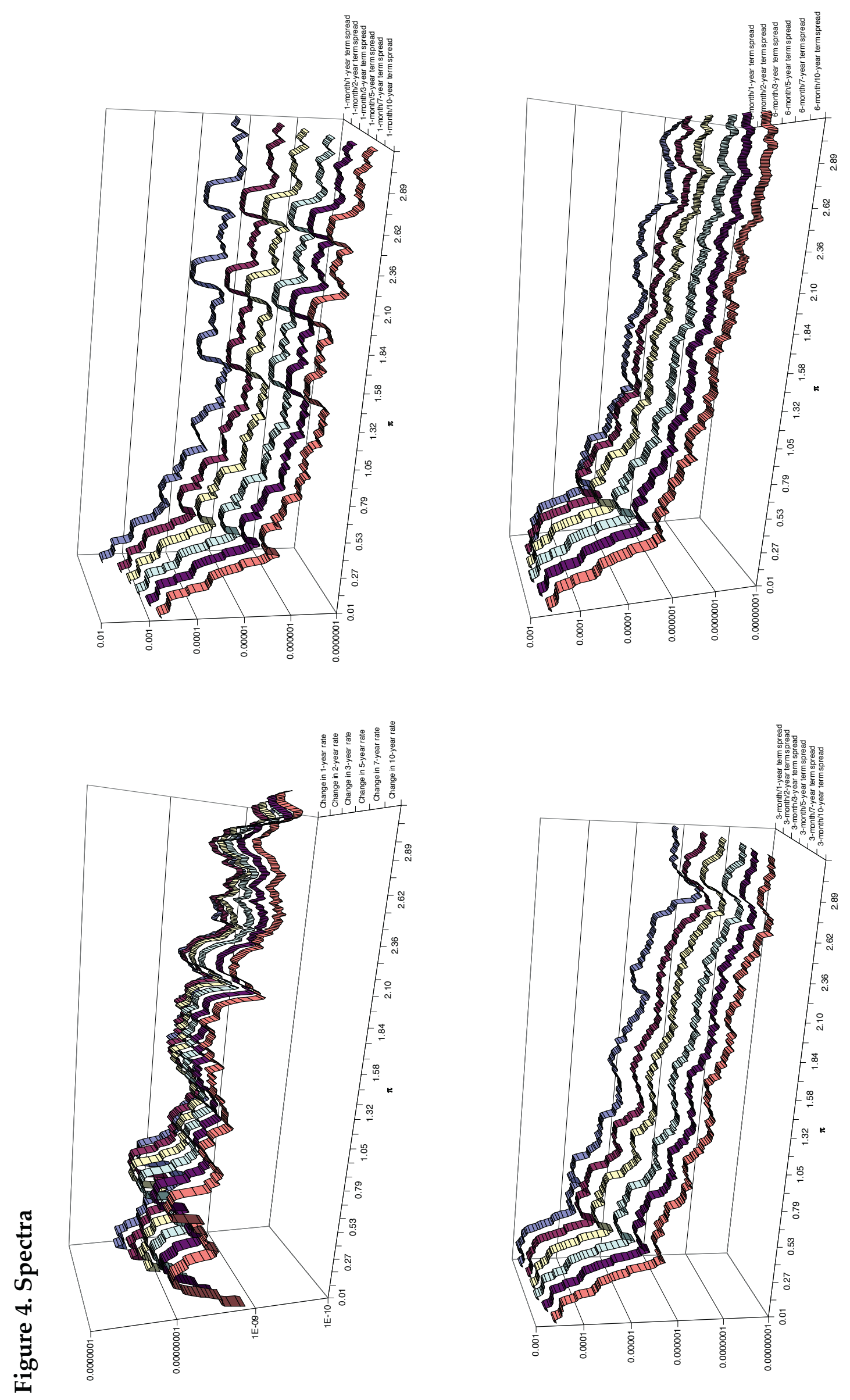
Figure 5. Estimated $\beta$ parameters across frequency bands

\section{1-month rate}

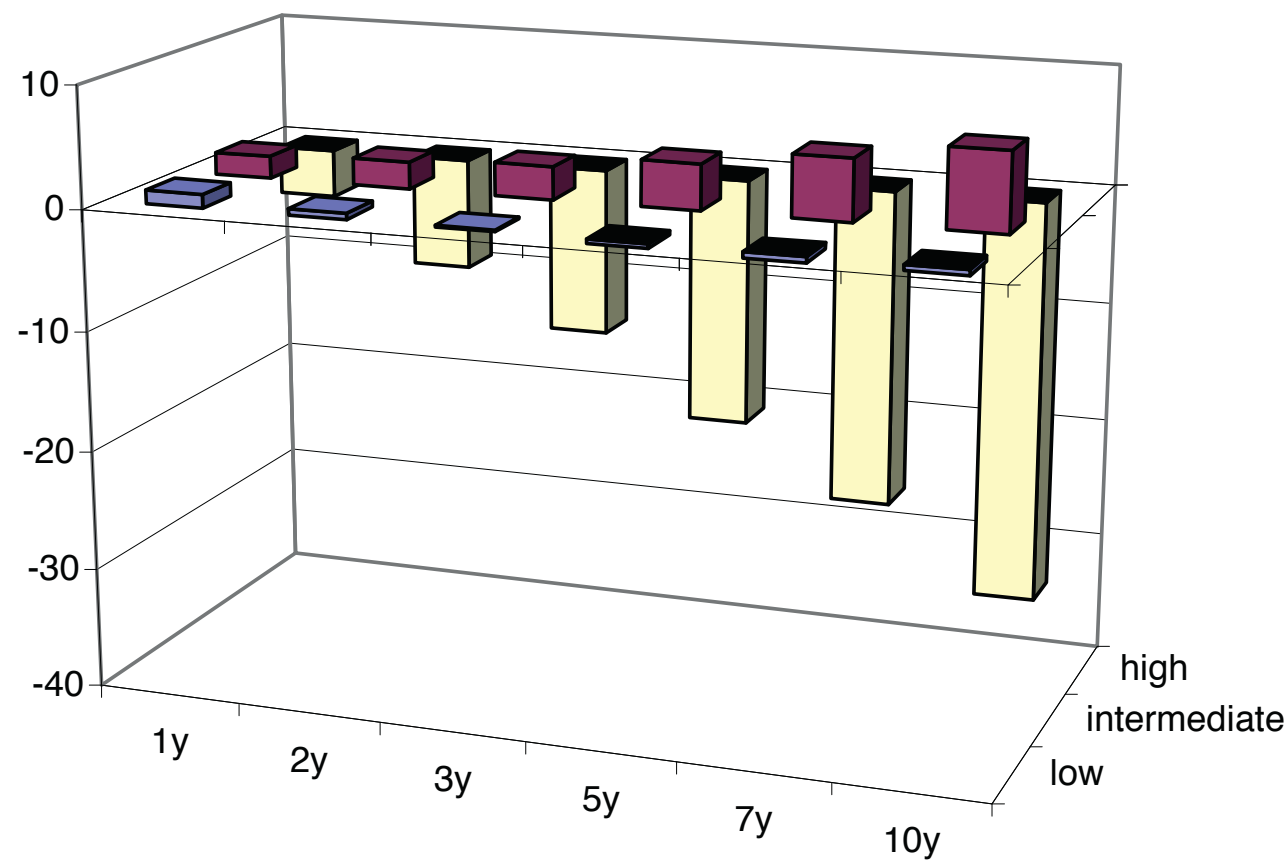

Figure 6. Estimated $\beta$ and plim $\beta$

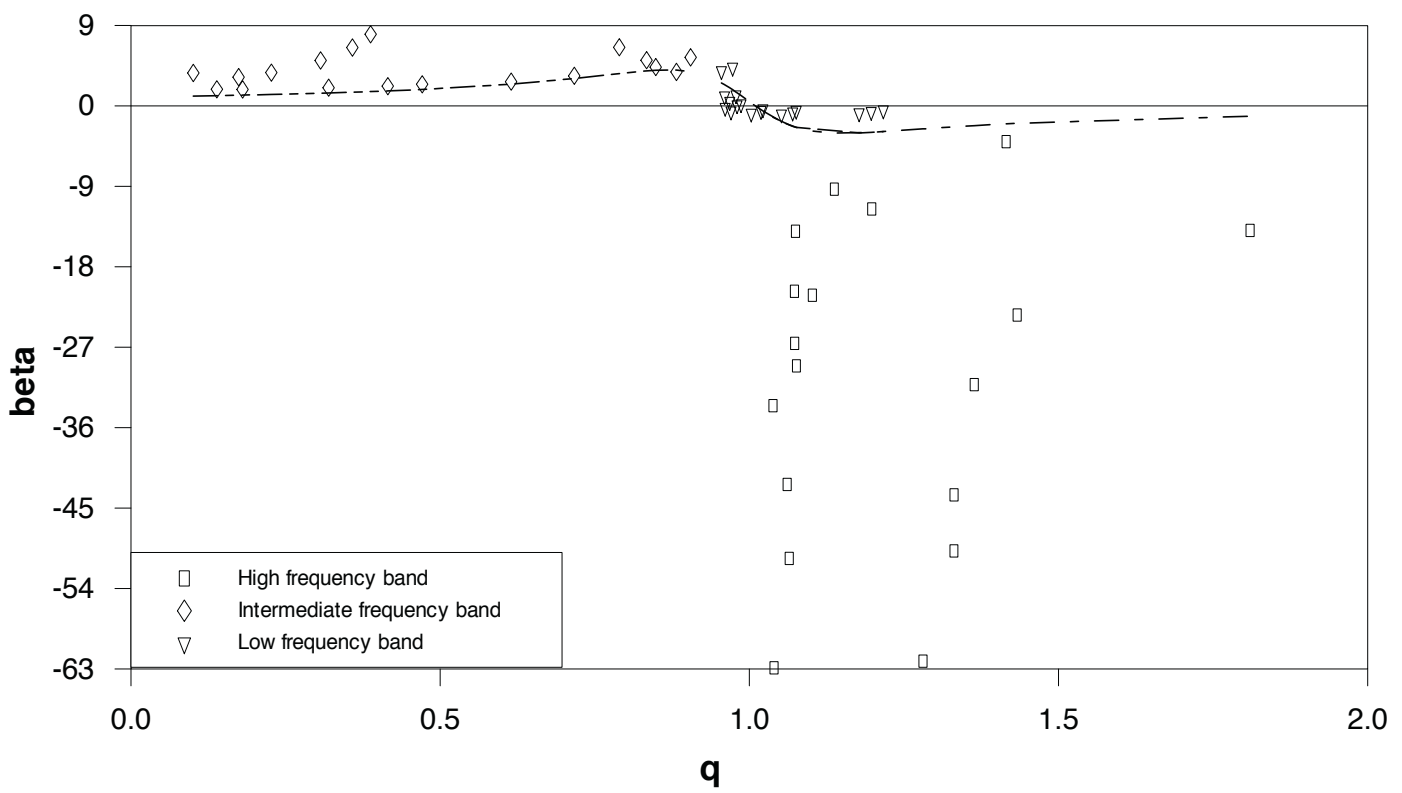




\section{European Central Bank Working Paper Series}

For a complete list of Working Papers published by the ECB, please visit the ECB's website (http://www.ecb.europa.eu).

929 "Real convergence in Central and Eastern European EU Member States: which role for exchange rate volatility?" by O. Arratibel, D. Furceri and R. Martin, September 2008.

930 "Sticky information Phillips curves: European evidence" by J. Döpke, J. Dovern, U. Fritsche and J. Slacalek, September 2008.

93I "International stock return comovements" by G. Bekaert, R. J. Hodrick and X. Zhang, September 2008.

932 "How does competition affect efficiency and soundness in banking? New empirical evidence" by K. Schaeck and M. Čihák, September 2008.

933 "Import price dynamics in major advanced economies and heterogeneity in exchange rate pass-through" by S. Dées, M. Burgert and N. Parent, September 2008.

934 “Bank mergers and lending relationships" by J. Montoriol-Garriga, September 2008.

935 "Fiscal policies, the current account and Ricardian equivalence" by C. Nickel and I. Vansteenkiste, September 2008.

936 "Sparse and stable Markowitz portfolios" by J. Brodie, I. Daubechies, C. De Mol, D. Giannone and I. Loris, September 2008.

937 "Should quarterly government finance statistics be used for fiscal surveillance in Europe?" by D. J. Pedregal and J. J. Pérez, September 2008.

938 "Channels of international risk-sharing: capital gains versus income flows" by T. Bracke and M. Schmitz, September 2008.

939 “An application of index numbers theory to interest rates” by J. Huerga and L. Steklacova, September 2008.

940 "The effect of durable goods and ICT on euro area productivity growth?" by J. Jalava and I. K. Kavonius, September 2008.

941 “The euro's influence upon trade: Rose effect versus border effect” by G. Cafiso, September 2008.

942 “Towards a monetary policy evaluation framework” by S. Adjemian, M. Darracq Pariès and S. Moyen, September 2008.

943 "The impact of financial position on investment: an analysis for non-financial corporations in the euro area" by C. Martinez-Carrascal and A. Ferrando, September 2008.

944 "The New Area-Wide Model of the euro area: a micro-founded open-economy model for forecasting and policy analysis" by K. Christoffel, G. Coenen and A. Warne, October 2008.

945 "Wage and price dynamics in Portugal” by C. Robalo Marques, October 2008.

946 “Macroeconomic adjustment to monetary union” by G. Fagan and V. Gaspar, October 2008.

947 "Foreign-currency bonds: currency choice and the role of uncovered and covered interest parity" by M. M. Habib and M. Joy, October 2008. 
948 "Clustering techniques applied to outlier detection of financial market series using a moving window filtering algorithm" by J. M. Puigvert Gutiérrez and J. Fortiana Gregori, October 2008.

949 “Short-term forecasts of euro area GDP growth” by E. Angelini, G. Camba-Méndez, D. Giannone, L. Reichlin and G. Rünstler, October 2008.

950 "Is forecasting with large models informative? Assessing the role of judgement in macroeconomic forecasts" by R. Mestre and P. McAdam, October 2008.

951 "Exchange rate pass-through in the global economy: the role of emerging market economies" by M. Bussière and T. Peltonen, October 2008.

952 "How successful is the G7 in managing exchange rates?" by M. Fratzscher, October 2008.

953 "Estimating and forecasting the euro area monthly national accounts from a dynamic factor model" by E. Angelini, M. Bańbura and G. Rünstler, October 2008.

954 “Fiscal policy responsiveness, persistence and discretion" by A. Afonso, L. Agnello and D. Furceri, October 2008.

955 “Monetary policy and stock market boom-bust cycles" by L. Christiano, C. llut, R. Motto and M. Rostagno, October 2008.

956 "The political economy under monetary union: has the euro made a difference?" by M. Fratzscher and L. Stracca, November 2008.

957 "Modeling autoregressive conditional skewness and kurtosis with multi-quantile CAViaR" by $\mathrm{H}$. White, T.-H. Kim, and S. Manganelli, November 2008.

958 “Oil exporters: in search of an external anchor” by M. M. Habib and J. Stráský, November 2008.

959 “What drives U.S. current account fluctuations?” by A. Barnett and R. Straub, November 2008.

960 “On implications of micro price data for macro models” by B. Maćkowiak and F. Smets, November 2008.

96I "Budgetary and external imbalances relationship: a panel data diagnostic" by A. Afonso and C. Rault, November 2008.

962 "Optimal monetary policy and the transmission of oil-supply shocks to the euro area under rational expectations" by S. Adjemian and M. Darracq Pariès, November 2008.

963 "Public and private sector wages: co-movement and causality" by A. Lamo, J. J. Pérez and L. Schuknecht, November 2008.

964 “Do firms provide wage insurance against shocks? Evidence from Hungary” by G. Kátay, November 2008.

965 “IMF lending and geopolitics” by J. Reynaud and J. Vauday, November 2008.

966 “Large Bayesian VARs” by M. Bańbura, D. Giannone and L. Reichlin, November 2008.

967 "Central bank misperceptions and the role of money in interest rate rules" by V. Wieland and G. W. Beck, November 2008.

968 “A value at risk analysis of credit default swaps” by B. Raunig and M. Scheicher, November 2008.

969 "Comparing and evaluating Bayesian predictive distributions of asset returns" by J. Geweke and G. Amisano, November 2008. 
970 "Responses to monetary policy shocks in the east and west of Europe” by M. Jarociński, November 2008.

97I "Interactions between private and public sector wages" by A. Afonso and P. Gomes, November 2008.

972 "Monetary policy and housing prices in an estimated DSGE for the US and the euro area" by M. Darracq Pariès and A. Notarpietro, November 2008.

973 "Do China and oil exporters influence major currency configurations?" by M. Fratzscher and A. Mehl, December 2008.

974 “Institutional features of wage bargaining in 23 European countries, the US and Japan” by P. Du Caju, E. Gautier, D. Momferatou and M. Ward-Warmedinger, December 2008.

975 "Early estimates of euro area real GDP growth: a bottom up approach from the production side" by E. Hahn and F. Skudelny, December 2008.

976 "The term structure of interest rates across frequencies" by K. Assenmacher-Wesche and S. Gerlach, December 2008. 
